\title{
Educación intercultural bilingüe, privatización por defecto y desigualdad entre los docentes awajún de la región San Martín ${ }^{1}$
}

\author{
Marianella Zúñiga \\ Universidad Federal de Minas Gerais-UFMG \\ marianellazunigarebaza@gmail.com
}

Recibido: 04/09/2018

Aprobado: 25/07/2019

1. El artículo ha sido desarrollado sobre la base de mi tesis para obtener el grado de Magíster en ciencias sociales con orientación en educación por la Flacso, sede académica Argentina. Fue asesorada por las doctoras Ana Carolina Hecht y Patricia Ames. Se encuentra disponible en http://repositorio.flacsoandes.edu.ec/ handle/10469/13178\#.Wpc6L6iWa1s. 


\title{
Educación intercultural bilingüe, privatización por defecto y desigualdad entre los docentes awajún de la región San Martín
}

\section{Resumen}

El artículo aborda las implicancias de la privatización de la educación y la formación docente de maestros awajún en la reproducción de desigualdad en la Educación Intercultural Bilingüe (EIB), política educativa dirigida a los pueblos indígenas en el Perú. En el contexto de implementación de políticas educativas neoliberales, en 1996, se promulgó el Decreto Legislativo 882, lo que generó el notable incremento de la educación privada en el país. Aunque pobremente regulado por el Estado, un sector de la oferta privada resulta atractivo para los maestros awajún de la región San Martín, quienes trabajan en el servicio de EIB en un contexto caracterizado por el déficit de maestros indígenas con formación profesional concluida. Sin embargo, el acceso a la educación privada de cuestionable calidad y probidad participa de la creciente devaluación del rol del maestro awajún y en la configuración de circuitos educativos desiguales. La investigación cualitativa involucró la construcción de datos a través de entrevistas, encuestas y observaciones en las que participaron estudiantes y maestros awajún, así como docentes no indígenas de institutos pedagógicos y universidades en las ciudades de Moyobamba, Rioja, Nueva Cajamarca y Jaén. Además, la investigación utilizó documentos oficiales sobre la privatización de la educación, la formación docente y la política de EIB durante el período de 1990 al 2015.

Palabras clave: Educación intercultural bilingüe, privatización de la educación, formación docente, desigualdad, pueblos indígenas

\section{Intercultural and bilingual education, privatization of education and inequality among Awajun teachers in San Martin region}

\begin{abstract}
This paper explores some effects of the privatization of education and Awajun teacher training in the reproduction of inequality in the Educación Intercultural Bilingüe (EIB), main education policy for indigenous peoples in Peru. Since Legislative Decree $N^{\circ} 882$ was promulgated in 1996, within the context of neoliberal policies, private education grew enormously. Although scarcely supervised by the State, this education offer became attractive to Awajun teachers from San Martin, who work in the EIB service, in which indigenous teachers with professional degrees are scant. However, the engagement with private education contributes to the increasing devaluation of Awajun teachers' roles and to the configuration of unequal educative networks. This qualitative research is based on information collected from interviews, observations and surveys with Awajun students and teachers, as well as with non-indigenous teacher trainers from public and private institutions in the cities of Moyobamba, Rioja, Nueva Cajamarca, and Jaén. In a complementary way, the study bases on official documents regarding the privatization of education, teacher training and EIB policy during the period of 1990 to 2015.
\end{abstract}

Keywords: Intercultural and bilingual education, privatization of education, teacher training, inequality, indigenous people. 


\section{Introducción}

El carácter pluriétnico y multilingüe de la sociedad peruana no solo se asocia con una valiosa heterogeneidad cultural y lingüística, sino también con brechas sociales, económicas y políticas. Un ejemplo de ello es que el $46 \%$ de estudiantes indígenas no reciben cobertura educativa en lengua indígena (Cáceres, Cavero y Gutiérrez, 2016). Solo el 27\% de los estudiantes de las escuelas EIB alcanzaron el logro esperado en castellano como segunda lengua en la Evaluación Censal del Estudiante del año 2015 (Consejo Nacional de Educación, 2016). Además, la formación profesional de los maestros que trabajan en el servicio de EIB es un asunto muy postergado en el país.

En la actualidad muchos maestros del pueblo indígena awajún, quienes viven en el Alto $\mathrm{Mayo}^{2}$, se financian una formación profesional en instituciones de bajo costo en el contexto del crecimiento explosivo de la educación privada. De hecho, aproximadamente, la mitad de los maestros awajún del Alto Mayo son, a su vez, estudiantes de una filial de una universidad y un instituto superior pedagógico (ISP), ambos privados, ubicados en la ciudad de Jaén, región Cajamarca. Así, acceden a la especialidad de educación primaria en la modalidad conocida, localmente, como "a distancia" o "semipresencial"3.

El presente artículo se organiza en cinco partes. En la primera, se desarrolla la aproximación metodológica y teórica que orientó la investigación. En una segunda parte, se amplía el escenario educativo donde se llevó a cabo el trabajo de campo. A partir del análisis de algunos fragmentos de entrevistas, se advierte el creciente descrédito que atraviesa el maestro awajún producto de su acceso a programas de formación docente que responden a la privatización por defecto (Balarín, 2012, 2015, 2017). En una tercera parte, se analizan las repercusiones del traslape entre la privatización por defecto y la EIB en la reproducción de desigualdad en la educación, así como entre los awajún. En una cuarta parte, se discute de qué manera esta oferta educativa interpela la relación entre el Estado y el ciudadano awajún del Alto Mayo. Finalmente, se señalan algunas recomendaciones.

2. En la zona alta de la cuenca del río Mayo, región San Martín, vive el pueblo indígena awajún. A partir de ello, se establece la denominación de uso común los awajún del Alto Mayo. Sin embargo, los awajún viven mayoritariamente en la región Amazonas, y, en menor número, en regiones como San Martín; Loreto; Cajamarca; y, en la actualidad, también en Ucayali. Su población se estima en 67,772 habitantes (Cáceres, Cavero y Gutiérrez, 2016), siendo el segundo pueblo amazónico con mayor población. Para estudios etnográficos sobre los awajún del Alto Mayo, se puede consultar Brown $(2014,1984)$ y Greene (2009).

3. De acuerdo con la página web de la filial de la universidad privada, el costo de la mensualidad de la especialidad de educación es de 200 soles; y el costo de la matrícula, de 220 soles. 


\section{Aproximación metodológica y teórica}

\section{Metodología}

Se trata de un estudio cualitativo e interpretativo que buscó profundizar en los significados asociados a la formación docente de los maestros bilingües del Alto Mayo por parte de algunos docentes y estudiantes awajún; de este modo, se da cuenta de las repercusiones de la privatización de la educación en la EIB, así como en dicho pueblo indígena.

En las márgenes izquierda y derecha del Alto Mayo, en las provincias de Moyobamba y Rioja, existen alrededor de 36 escuelas EIB (16 del nivel inicial, 18 del nivel primaria y 2 del nivel secundaria) y 75 docentes awajún en los niveles de primaria y secundaria (Ministerio de Educación, 2016b). La muestra del estudio estuvo formada por siete docentes awajún destacados - cinco hombres y dos mujeres- quienes estudiaron en ISP públicos. Cuatro de ellos son egresados de ISP públicos ubicados en la provincia de Moyobamba y en la ciudad de Jaén, región Cajamarca, donde estudiaron en la modalidad de profesionalización docente ${ }^{4}$. Los tres maestros restantes accedieron a una formación docente inicial en educación bilingüe y educación intercultural bilingüe en ISP públicos en las regiones Ucayali y Loreto. Es decir, todos los docentes de la muestra provienen de ISP públicos; la mayoría de ellos, de programas denominados bilingües o interculturales bilingües. Su formación superior difiere, principalmente, en la modalidad de formación a la que accedieron, sea esta una formación docente inicial o una profesionalización.

En relación con la labor profesional realizada por los siete docentes durante el trabajo de campo, dos de ellos se encontraban en los organismos locales del sector educativo (UGEL); dos, en programas de soporte pedagógico del Ministerio de Educación de Perú; uno, en un programa de formación docente bilingüe en una universidad católica; y dos eran maestros en dos escuelas primarias de dos comunidades nativas ubicadas en el distrito de Awajún, provincia de Rioja, ámbito cercano a la Carretera Marginal. Adicionalmente, sus experiencias profesionales indican que han transitado por organismos intermedios del Ministerio de Educación (DRE), otros programas de soporte pedagógico del Ministerio de Educación, proyectos de ONG, así como cargos políticos en municipalidades, sindicatos bilingües y organizaciones indígenas. En ese sentido, se trata de un grupo destacado de maestros awajún, quienes cuentan con particulares trayectorias educativas y laborales. Sus perfiles contrastan con los de un buen número de estudiantes-docentes awajún, que trabajan en escuelas

4. La formación pedagógica inicial indica la realización de estudios en educación antes de iniciado el ejercicio profesional. En cambio, la profesionalización docente, la modalidad semipresencial o a distancia hacen referencia, en el presente artículo, a la preparación profesional de los maestros que ejercen la docencia sin haber concluido su formación pedagógica. 
bilingües del Alto Mayo y acceden a la oferta privada de los programas de formación docente en la modalidad semipresencial o a distancia en Jaén.

Con respecto a las técnicas de construcción de datos, se recurrió a conversaciones, entrevistas y encuestas. La entrevista semiestructurada fue la técnica más utilizada con los docentes destacados. ${ }^{5}$. Asimismo, se realizaron encuestas a 2 grupos de aproximadamente 30 estudiantes-maestros del programa de profesionalización del ISP público de tradición en la ciudad de Jaén, de donde egresaron 2 docentes del grupo de maestros destacados. Se encuestó a un grupo de diez jóvenes estudiantes del programa de formación inicial de una reconocida universidad católica en el distrito de Nueva Cajamarca. En ambos casos, se buscó conocer las opiniones de los estudiantes sobre la formación de maestros indígenas en los institutos y universidades privados, surgidos en los últimos años en Jaén.

Se realizaron algunas observaciones y conversaciones en el ISP público en Jaén y la universidad católica en Nueva Cajamarca, donde se concentran un buen número de estudiantes de diferentes pueblos indígenas que viven en las regiones de Amazonas, Cajamarca y San Martín, a fin de ampliar los datos construidos a través de las entrevistas y encuestas. Debido a la ambigüedad en la formalidad de los programas ofertados por los centros de educación superior privados de Jaén (ISP y filial de universidad), la observación en el ISP privado y el diálogo con el responsable de la filial de la universidad fueron breves.

A partir de ello, se logró comparar los centros de formación a los que acceden los maestros awajún, en relación con la infraestructura y los servicios ofrecidos. Así mismo, fue posible ponderar el esfuerzo que significa para los maestros indígenas su traslado a Jaén y el financiamiento de su formación profesional.

5. El estudio contempla otras fuentes de información, por lo que se entrevistó al presidente de la organización política indígena del Alto Mayo, a docentes no indígenas de los ISP y de universidades públicas que brindan formación docente inicial, a dos docentes de un ISP público de tradición en Jaén, así como a la coordinadora de una universidad católica privada en Nueva Cajamarca. Además, se realizó una entrevista a la directora de la Dirección General de Educación Intercultural Bilingüe Rural y Alternativa (Digeibira) del Ministerio de Educación, organismo responsable de la política de educación intercultural bilingüe (EIB) en el país. 
Tabla 1. Volumen de los datos analizados

\begin{tabular}{|c|c|c|c|}
\hline Técnica & Sujetos e instituciones & Número & Lugar \\
\hline \multirow{5}{*}{ Entrevistas } & Docentes awajún & 7 & $\begin{array}{l}\text { Moyobamba y } \\
\text { Rioja, San Martín }\end{array}$ \\
\hline & $\begin{array}{l}\text { Organización indígena del } \\
\text { Alto Mayo }\end{array}$ & 1 & $\begin{array}{l}\text { Moyobamba, San } \\
\text { Martín }\end{array}$ \\
\hline & $\begin{array}{l}\text { Docentes no indígenas } \\
\text { de programas regulares } \\
\text { en un ISP público y } 2 \\
\text { universidades. }\end{array}$ & 5 & $\begin{array}{l}\text { Moyobamba, Rioja } \\
\text { y Nueva Cajamarca, } \\
\text { San Martín. }\end{array}$ \\
\hline & $\begin{array}{l}\text { Directora de la Dirección } \\
\text { de Educación Básica } \\
\text { Alternativa, Intercultural } \\
\text { Bilingüe y de Servicios } \\
\text { Educativos en el Ámbito } \\
\text { Rural }\end{array}$ & 1 & Lima \\
\hline & Total & 14 & \\
\hline \multirow{4}{*}{$\begin{array}{l}\text { Observaciones } \\
\text { y conversaciones }\end{array}$} & ISP público "BA" & 6 & \\
\hline & Universidad privada "UD" & 1 & Jaén, Cajamarca \\
\hline & ISP privado "JP" & 1 & \\
\hline & Total & 8 & \\
\hline \multirow{3}{*}{ Encuestas } & ISP público "BA" & $\begin{array}{c}1 \text { encuesta a } 30 \\
\text { estudiantes }\end{array}$ & Jaén, Cajamarca \\
\hline & $\begin{array}{l}\text { Universidad católica } \\
\text { privada }\end{array}$ & $\begin{array}{c}1 \text { encuesta a } 10 \\
\text { estudiantes }\end{array}$ & $\begin{array}{l}\text { Nueva Cajamarca, } \\
\text { San Martín }\end{array}$ \\
\hline & Total & 3 & \\
\hline
\end{tabular}

Fuente: Elaboración propia, basada en el material recopilado durante el trabajo de campo.

\section{Marco teórico}

A continuación, se desarrollan tres nociones que permiten ahondar en los vínculos entre la privatización de la educación, la formación pedagógica de los maestros awajún y sus repercusiones en la EIB. El contexto de políticas educativas neoliberales provee el marco en el que se llevó a cabo la privatización de la educación, que se reconfiguró de acuerdo con las características del Estado. Asimismo, el concepto de desigualdad permite comprender las particularidades del sistema educativo peruano, así como aproximarse a las renovadas implicancias de la privatización de la educación en la EIB y en el pueblo awajún. 


\section{- Políticas educativas neoliberales}

Las políticas educativas neoliberales corresponden a una agenda global que produjo políticas de gobierno de la educación similares, a nivel formal, en muchos países. Sin embargo, las consecuencias de estos procesos dependen de cómo las reformas han sido reapropiadas en diferentes contextos (Balarín, 2012).

La segunda mitad de la década de 1980 dejó al Estado incapacitado de proveer bienes y servicios sociales, así como a un país asolado por el conflicto armado interno y la hiperinflación (Pease y Romero, 2013). Las políticas educativas de los años 90 se implementaron en un escenario de grave crisis económica y política, en el que resultó indispensable la "modernización" del Estado y la reincorporación del país a los mercados internacionales (Cuenca, 2013). Así, en la década de 1990, se inició la aplicación de reformas para instalar la forma de gobierno neoliberal bajo un régimen dictatorial (Oliart, 2007).

Según Gentili (1998), las políticas neoliberales asumen que una mayor presencia del mercado permitiría "solucionar" los problemas educativos. De acuerdo con Balarín (2012), en el Perú, se buscó crear un mercado educativo que promoviera la transferencia de la conducción y gestión de los centros educativos públicos a entidades promotoras. Esta medida obtuvo el rotundo rechazo de grupos organizados de la sociedad civil y el Sindicato Único de Trabajadores de la Educación (Sutep), que sintieron amenazada la gratuidad de la enseñanza. Entonces, se llevaron a cabo modificaciones, menos directas, bajo el supuesto de que generarían menos oposición. En este escenario, en 1996, se promulgó una política que impactó decisivamente en el escenario educativo posterior: el Decreto Legislativo $\mathrm{N}^{\circ} 882$ o "Ley de promoción de la inversión en Educación". Como consecuencia, se originó el aumento explosivo de la oferta educativa privada en el país. Además, para Balarín (2017), la notable expansión de la educación privada se explicaría por el progresivo deterioro de la educación pública en el país, así como por el incremento del poder adquisitivo de un buen número de familias peruanas durante el período de crecimiento económico en lo que va del siglo XXI.

\section{- Privatización de la educación}

La configuración de la educación en países en desarrollo ha implicado no solo la participación del Estado, sino también del sector privado, como en el caso de las ONG (Ball y Youdell, 2007). Si bien la participación del sector privado en la educación peruana no ha surgido en las últimas décadas, la transformación de la educación pública en un espacio abierto al lucro privado sí es un fenómeno reciente (Balarín, 2015). Las matrices políticas, sociales y culturales que caracterizan a las sociedades y Estados participan en la resignificación de las pautas de privatización (Ball, 2007; Ball y Youdell, 2014). 
De ese modo, la "privatización educativa" es un concepto que se reconfigura de acuerdo con contextos particulares, lo mismo que sus implicancias (Balarín, 2015). Balarín (2015) identifica formas de privatización "por diseño" y "por defecto". En primer lugar, la privatización "por diseño" es generada por políticas cuyo objetivo es privatizar algunas dimensiones de los sistemas educativos o introducir mecanismos de mercado en la educación pública que producen cuasi mercados educativos. La privatización “por diseño" involucra a la privatización endógena y la exógena: la primera refiere a la privatización en la educación pública, mientras que la segunda, a la privatización de la educación pública (Ball, 2007; Ball y Youdell, 2014; Balarín, 2015). La privatización endógena implica la introducción de políticas de cuasi mercados en la educación pública. Por su parte, la privatización exógena supone la participación del sector privado en la educación pública, lo cual se manifiesta con claridad en países que no universalizaron el sistema educativo (Balarín, 2015).

En segundo lugar, la privatización "por defecto" sucede en contextos de alta debilidad institucional y no es producto de políticas de privatización disenadas explícitamente. Sin embargo, Balarín (2015) precisa que la privatización por defecto puede ser generada de forma más o menos directa por políticas de liberalización, y de promoción de la inversión privada en la educación, como el DL 882. Esta privatización se origina a partir de demandas de la población que encuentra carencias en la oferta educativa pública. Por este motivo, surge en países donde el acceso y la calidad de la oferta educativa son asuntos relegados (Balarín, 2015).

La privatización en Estados con marcos reguladores limitados profundizaría tendencias de segregación, debido a que su implementación no es efectiva. En la privatización por defecto, las limitaciones de regulación son más pronunciadas, pues el fenómeno no es generado por políticas claras y, por ello, no sería visibilizado ni discutido en el ámbito público (Balarín, 2015). Aún más, en los países donde la privatización ha ocurrido por defecto, donde la regulación y la capacidad institucional son precarias, una parte de la oferta no alcanzaría estándares mínimos de calidad; incluso, se daría la posibilidad de prácticas de corrupción (Balarín, 2015). Ello repercute, sobre todo, en la población de escasos recursos, que accede a un sector del fenómeno de la privatización por defecto: la educación de bajo costo.

\section{- Desigualdad}

En la segunda mitad del siglo XX, se amplió el acceso a la educación de sectores rurales y pobres en el país, pero no se generaron impactos en los resultados de este acceso. Así, se democratizó el acceso a la escuela a costa de los resultados de la enseñanza, lo cual produjo desigualdad (Benavides, 2007).

En el Perú, la escuela mantiene un rol contradictorio, al ser una institución que promueve una meta democrática como es la ciudadanía, pero, al mismo tiempo, posee un rol diferenciador, cuyo objetivo es formar individuos produc- 
tivos para el trabajo (Benavides, 2007). De ese modo, una mayor igualdad de acceso y de oportunidades en la educación no llevó a una mayor igualdad en los resultados de la educación (Dubet, 2015).

Dubet (2015) desarrolla tres tipos de nociones de justicia a partir de los cuales pueden ser analizados los sistemas escolares: los conceptos de "igualdad de acceso", "igualdad de oportunidades" e "igualdad de resultados". La más básica de las injusticias escolares fueron las desigualdades de acceso a una formación elemental, por lo que la escolarización para todos se constituyó como una importante causa de combate por la justicia escolar. Así, la igualdad de acceso se impone a fines del siglo XIX en Europa y en los Estados Unidos de América como un criterio de justicia. Cabe anotar que es posible que la igualdad de acceso no plantee mayores contradicciones en sociedades integradas y democráticas, distantes a la realidad del país.

El modelo de igualdad de oportunidades esperaba que se sustituyeran las herencias sociales y se considerara únicamente el mérito de los individuos. Dicho modelo se soporta en el presupuesto de que las desigualdades escolares son justas, porque surgen de una competencia equitativa que neutralizaría los efectos de las desigualdades sociales. Al respecto, Dubet (2005) afirma que la igualdad meritocrática de oportunidades es el modelo de justicia escolar dominante en las sociedades democráticas, debido a que se fundamenta en los principios centrales de la sociedad moderna e industrial: la igualdad entre los individuos y la división del trabajo. Si bien la igualdad de oportunidades tiene el centro de interés en la competencia escolar, no apunta a la igualdad de resultados obtenidos en los alumnos. Sin embargo, en la década de 1960, se evidenció que los alumnos provenientes de sectores vulnerables poseían menos oportunidades de éxito en la escuela. Estas brechas educativas, en el caso del Perú, ponen en cuestión profundamente la idea de una escuela que brinda igualdad de oportunidades en una sociedad poscolonial y marcada por el racismo (Oliart, 2007). Así, la escuela se mostraba incapaz de neutralizar las desigualdades sociales y culturales; aún más, tendía a favorecer y a legitimar la consolidación de una élite y de las desigualdades sociales.

Por su parte, la perspectiva de igualdad de resultados es concebida en términos de competencia equitativa y tiene como finalidad la reducción de las diferencias y el perfeccionamiento de la condición social de los más desfavorecidos. Sobre esta base, apunta a una proximidad en los resultados de los más y menos aventajados. La igualdad de resultados en ese marco sugiere el fortalecimiento de la escolaridad común y se interesa por el efecto de las desigualdades escolares sobre las desigualdades sociales resultantes (Dubet, 2015). Esta perspectiva considera que un buen sistema escolar es aquel que limita las desigualdades, así sea a costa de la movilidad.

Como plantea Oliart,

Diversos autores concuerdan en que la principal tensión en el sistema educativo peruano es la discrepancia entre las altas expectativas y el 
importante nivel de inversión que las clases más pobres ponen en la educación de sus hijos, por un lado, y la baja inversión del Estado y los terribles resultados que el sistema produce, por el otro. $(2011$, p. 4)

Saavedra y Suárez (2002) señalan que el gasto por alumno — si bien pasó de US\$ 650 a US\$ 1100 anuales - es muy bajo en el Perú. En esta realidad, la población pobre destina una inversión mayor de sus ingresos en la educación de sus hijos, lo que explicaría una "voluntad de pago" (Saavedra y Suárez, 2002).

Guadalupe, Twanama y Castro (2018) afirman que la inversión pública en educación sufrió importantes modificaciones en el período comprendido entre 1950 hasta la actualidad. Desde mediados de la década de 1960, el gasto por estudiante decreció notoriamente hasta la década de 1990. Dicho gasto se recupera en los años 90 y aumenta mucho más en el siglo XXI. No obstante, los resultados educativos se verían obstaculizados, como consecuencia de los años de crisis educativa y de una inadecuada inversión (Guadalupe, Twanama y Castro, 2018).

En el contexto de lo que podría denominarse una "educación pobre para pobres” (Oliart, 2007), en la década de 1990, comenzó el crecimiento desordenado de instituciones educativas que respondía a la privatización por defecto. Dentro del fenómeno, se ubica una oferta educativa privada de bajo costo y de baja intensidad (Balarín, 2015), a partir de lo cual se profundizaría la desigualdad en el sistema educativo.

En suma, el concepto de privatización por defecto permite entender que la privatización de la educación no se trata de un fenómeno homogéneo; antes bien, se recrea de acuerdo con las características de los Estados. De hecho, una mayor presencia del mercado en la educación en un contexto de debilidad regulatoria ha producido en el Perú una oferta de educación privada de bajo costo con una cuestionable intensidad formativa que perjudica, principalmente, a la población desfavorecida.

\section{Escenario educativo local y descrédito del docente awajún}

Las implicancias del traslape entre la privatización por defecto y la formación docente de estudiantes-maestros awajún son reflejadas en los cuestionamientos hacia el maestro awajún por parte de los docentes entrevistados. Los docentes entrevistados y los estudiantes-maestros encuestados, consultados sobre la realidad de la educación en las comunidades del Alto Mayo, refirieron que "uno de los desafíos más grandes es el docente indígena", en lo que también coincidió la directora de la Digeibira.

Para la Digeibira, el perfil del maestro indígena implica características como la formación en EIB y el manejo de estrategias para escuelas unidocentes y multigrado, la capacidad para incentivar la participación de familias y comunidad en la gestión pedagógica e institucional de la escuela, así como el 
compromiso con el aprendizaje de los estudiantes. De igual modo, dicho perfil supone ejercer liderazgo y autoridad en la comunidad, y poseer una conducta con valores éticos y coherentes con la comunidad (Ministerio de Educación, 2013). Para los docentes awajún entrevistados, el docente indígena debe contar con, al menos, formación pedagógica en instituciones que no formen parte del fenómeno de la privatización por defecto. Sin embargo, el perfil esperado por los docentes entrevistados y el requerido por el Ministerio de Educación es realmente escaso en el Alto Mayo.

A continuación, se identifican dos factores interrelacionados que permiten profundizar en el creciente descrédito que atraviesa el maestro awajún: la modalidad de formación docente a distancia y el acceso a la oferta de educación privada de bajo costo.

\section{Modalidades de formación docente}

Se desarrolla, como primer punto, el escenario de formación docente en la región San Martín y en la ciudad de Jaén a fin de señalar las diferencias entre la oferta pública y la oferta privada de bajo costo. Como segundo punto, se plantea la modalidad que permite "combinar" el trabajo en el aula con la formación profesional. A pesar de que este formato es ampliamente demandado por los awajún del Alto Mayo, solo es ofertado en instituciones privadas que no garantizan estándares mínimos.

\section{- ISP y universidades en la región San Martín y en la ciudad de Jaén}

En San Martín, la oferta de formación docente incluye diez institutos superiores pedagógicos (ISP), de los cuales seis son públicos y cuatro son privados ${ }^{7}$ (Montero, Ames, Uccelli y Cabrera, 2005). Un ISP se ubica en la capital, Moyobamba, y los demás en provincias. La universidad nacional, cuya facultad de Educación tiene sede en la ciudad de Rioja, no parece ocupar un lugar de liderazgo en la región (Montero, Ames, Uccelli y Cabrera, 2005).

El ISP emblemático en San Martín, el ISP Tarapoto, fundado en 1957, tuvo como antecedente la escuela normal de 1936 y concentra la matrícula más alta de la región (Montero et al., 2005). El segundo ISP en importancia es el de la capital, donde, de acuerdo con un docente entrevistado en la institución, prácticamente no existen estudiantes awajún. Sin embargo, mientras funcionó el programa de profesionalización docente, sí hubo concurrencia de estudiantesmaestros awajún. De hecho, una de las entrevistadas del grupo destacado de

6. En el contexto de la promoción de la educación privada sin regulación, esta modalidad permite combinar trabajo y formación, pero no garantiza la propia formación ni una posterior titulación.

7. Cabe precisar que, en la actualidad, el número de ISP públicos no ha variado; no obstante, es probable que el número de ISP privados haya incrementado. 
maestros awajún es egresada de este programa. En el ISP público de Moyobamba y en la universidad, se contabilizó solo dos estudiantes awajún matriculados en el año 2016. Cabe precisar que ninguna de las tres instituciones ofrece un programa de formación docente en Educación Intercultural Bilingüe y, en la actualidad, todas brindan una formación docente inicial.

La Universidad Católica inauguró el Centro de Investigación, Profesionalización y Extensión Universitaria para la Inclusión Social y el Desarrollo Regional en el distrito de Nueva Cajamarca en agosto del año 2010. Cuenta con la experiencia de desarrollar un programa de formación inicial dirigido a maestros indígenas en la ciudad de Atalaya, región Ucayali. Como en Atalaya, en la sede de Nueva Cajamarca, cuenta con un albergue para los estudiantes indígenas del programa de formación inicial, quienes provienen de diversos ámbitos de la Amazonía norte.

Ahora bien, durante los años 90, aumentó el número de instituciones públicas de educación superior y surgieron todas las instituciones privadas en la región San Martín, las que son consecuencia de la permisividad normativa de las autoridades para acreditar su funcionamiento (Montero et al., 2005). El incremento de la formación docente privada configura el escenario donde se desarrollan los programas de formación docente a distancia, a los que acceden los estudiantes-maestros awajún del Alto Mayo.

En la ciudad de Jaén, región Cajamarca, existe una oferta de formación docente privada en la modalidad a distancia o semipresencial, a la que asiste un mayor número de estudiantes-maestros Awajún. Ninguno de estos programas privados es de formación en EIB, y, además, existen serios cuestionamientos con respecto a su calidad y probidad ${ }^{8}$. En paralelo, existe un ISP público que cuenta con una reconocida trayectoria por los maestros indígenas de la zona y por algunos investigadores. De hecho, Oliart (2007), Díaz (2015) y Rivero (2007) reconocen la labor del ISP público en la formación de maestros rurales. Hasta hace unos cinco años, mientras se ofrecieron vacantes, los awajún optaron por el programa de dicho ISP. Estudiar la profesionalización docente en el ISP público en Jaén parece responder a cierto prestigio y tradición entre los maestros awajún. Es probable que, en vista de que el programa de profesionalización del ISP público de Jaén dejó de ofrecer vacantes, algunos estudiantesmaestros optaron por acceder a los programas privados.

8. La DRE Cajamarca suspendió la tramitación de expedientes administrativos por parte del ISP "JP", pues existe una denuncia penal en contra de sus directivos. El ISP inició el proceso de acreditación en el Sistema Nacional de Evaluación, Acreditación y Certificación (Sineace) en el año 2013, pero no se encuentra aún acreditado. De acuerdo con la Superintendencia Nacional de Educación Superior Universitaria (Sunedu), la universidad privada "UD" no cuenta con el debido licenciamiento y su filial en Jaén no se encuentra autorizada para prestar servicios universitarios. El actual rector de la UD ha postulado a la alcaldía de Chiclayo por el partido político Fuerza Popular, así como al Gobierno Regional de Lambayeque. 
En resumen, con respecto a las modalidades de formación docente identificadas, las tres instituciones públicas ubicadas en el Alto Mayo y el ISP público de Jaén brindan una formación docente inicial. Únicamente, el ISP privado y la filial de universidad privada de Jaén ofrecen programas de educación primaria en la modalidad a distancia.

\section{Modalidad a distancia o semipresencial}

Los estudiantes-maestros awajún demandan, en su mayoría, una formación docente que les permita también trabajar en las escuelas. No obstante, el ISP público de Jaén dejó de ofrecer el programa de titulación para maestros indígenas. Por lo tanto, un buen número de maestros awajún optó por acceder a los programas privados a distancia, a pesar de su desprestigio. Incluso, algunos jóvenes awajún del Alto Mayo decidieron abandonar la formación inicial en la universidad católica que incluye manutención (alojamiento y alimentación) y mensualidades con la finalidad de trasladarse a Jaén. La razón es que la formación inicial tiene mayores exigencias con respecto al tiempo de dedicación, lo cual no permite trabajar en las escuelas.

La mayoría de docentes destacados ${ }^{9}$ tiene cuestionamientos hacia dicha modalidad cuando proviene de los centros privados. Estos son concebidos como un negocio, en tanto no garantizan una adecuada preparación y titulación, lo que influye en la desvalorización del estudiante-maestro awajún. Entre algunos factores condicionantes de la preferencia por la formación docente a distancia por parte de los estudiantes-docentes awajún se encuentran los años de implementación de la modalidad de profesionalización docente, en particular, en el ISP público de renombre en Jaén; la precariedad económica de los maestros awajún, lo que influye en la búsqueda de una educación superior de la mano con un trabajo formal; la falta de información por parte de la población awajún sobre la desregulada oferta educativa privada; así como cierta complicidad por parte de algunos estudiantes-docentes que acceden a las instituciones educativas consideradas por algunos maestros y familias awajún como un "negocio" y una "estafa"

9. La modalidad que permite trabajar y profesionalizarse, ya sea privada o pública, obtuvo serios cuestionamientos por su menor intensidad formativa por parte de dos de los siete docentes destacados entrevistados y el líder político indígena.

10. Es decir, algunos awajún conocerían que las instituciones educativas son informales y, a pesar de ello, acceden a ellas. 


\section{Formación docente en el Alto Mayo}

En esta sección, se presentan cuatro gráficos que muestran el nivel de formación de los docentes de las UGEL de Moyobamba y Rioja ${ }^{11}$, así como el tipo de gestión de las instituciones en las que transcurrió su formación profesional.

Gráfico 1. Nivel de formación de los docentes awajún contratados en la UGEL Moyobamba (2015)

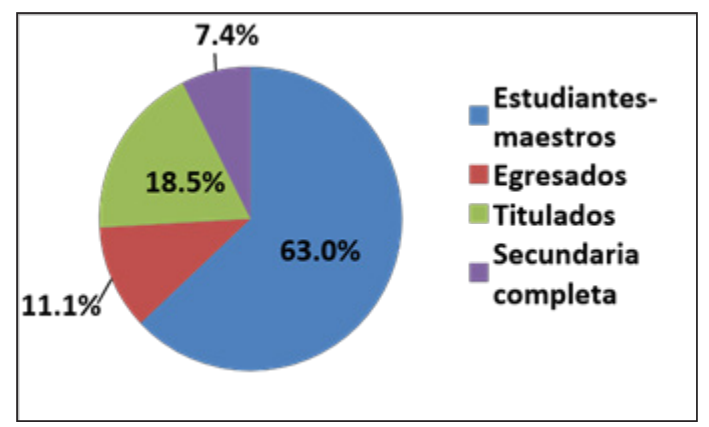

Fuente: Elaboración propia según actas de la UGEL

Gráfico 2. Docentes awajún con formación docente privada o pública en la UGEL Moyobamba (2015)

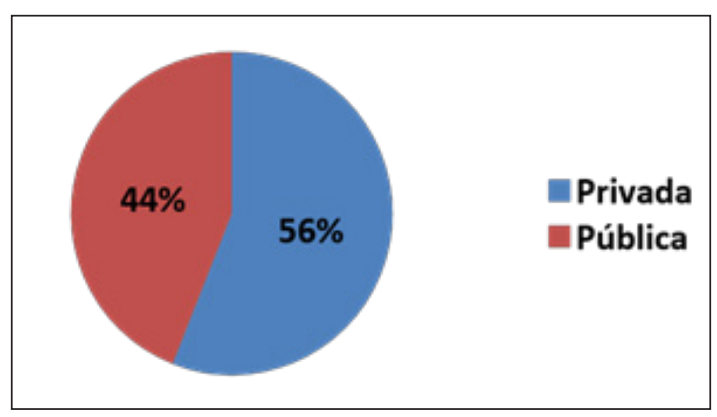

Fuente: Elaboración propia según actas de la UGEL.

11. La margen izquierda del Alto Mayo, donde se ubica la UGEL Moyobamba, posee menor acceso a servicios y mayor distancia respecto a ámbitos urbanos. De acuerdo con información del Ministerio de Educación (2016b), en la UGEL Moyobamba, existen 14 escuelas, 21 docentes y 369 alumnos en los niveles de inicial y primaria. En la UGEL Rioja, margen derecha del Alto Mayo, 16 escuelas, 36 docentes y 788 alumnos en los niveles de inicial y primaria. Además, existen dos colegios del nivel secundaria (Ministerio de Educación, 2016b). 
Gráfico 3. Nivel de formación de los docentes awajún contratados en la UGEL Rioja (2016)

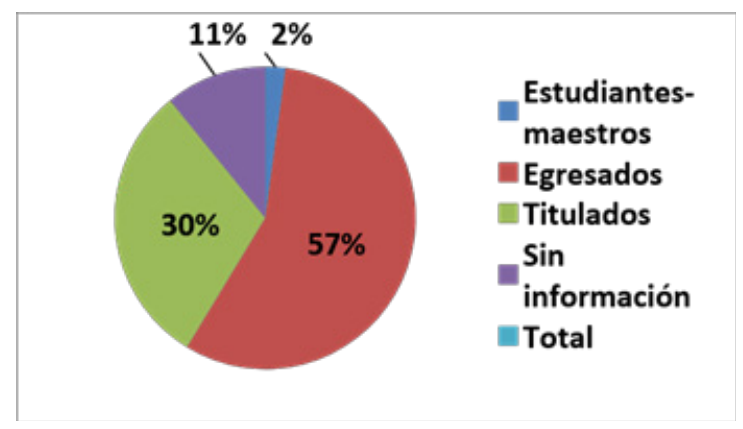

Fuente: Elaboración propia según actas de la UGEL.

Gráfico 4. Docentes awajún con formación docente privada o pública en la UGEL Rioja (2016)

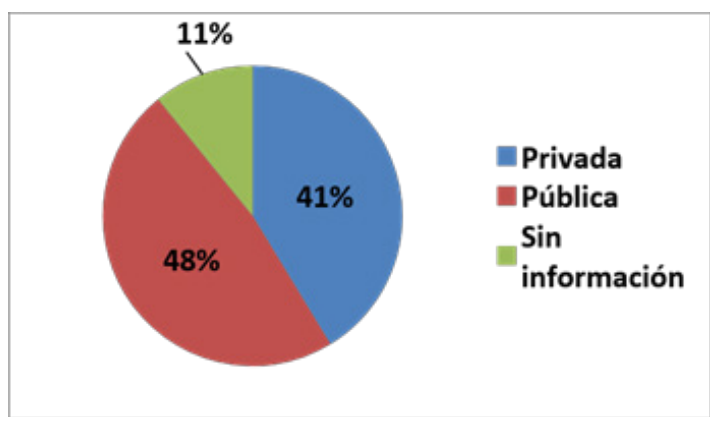

Fuente: Elaboración propia según actas de la UGEL.

Se observa que, de los 27 docentes (2 del nivel inicial y 25 del nivel primaria) que trabajan en escuelas bilingües pertenecientes a la UGEL Moyobamba, contratados en el 2015, 19 - es decir, el 70\% - no cuentan con formación pedagógica concluida. Además, ninguno de los cinco docentes titulados es egresado de la educación superior privada. Del total de docentes contratados por la UGEL Moyobamba en el 2015, más de la mitad (56\%) financia su formación en el instituto y filial de universidad privados en Jaén. En el caso de la UGEL Rioja, del total de 47 docentes awajún contratados para el nivel primaria en el 2016, se observa que el $87 \%$ cuenta con formación pedagógica concluida, pero no con título pedagógico. De ellos, el 30\% de los maestros cuentan con título. Aproximadamente, la mitad de los docentes estudian en centros de formación públicos, mientras que el $41 \%$ estudian en el instituto y la universidad privados de Jaén. Cabe anotar que no existen datos sobre la institución donde 
se formaron cinco docentes. En síntesis, alrededor de la mitad de los docentes awajún del Alto Mayo se encuentran matriculados, o bien son egresados del instituto privado y la filial de la universidad privada ubicados en Jaén.

A continuación, se presentan algunos fragmentos de entrevistas y encuestas realizadas a los maestros destacados y algunos estudiantes-maestros awajún a fin de revelar cómo conciben la oferta privada de formación docente. De ese modo, se problematizan las repercusiones de la formación profesional de los docentes bilingües en la reproducción de desigualdad en el sistema educativo, así como entre la población awajún del Alto Mayo.

\section{- Cuestionamientos de los docentes destacados hacia la educación privada a distancia}

Tomás ${ }^{12}$, el más joven de los docentes entrevistados, trabaja en una comunidad cercana a la Carretera Marginal y fue cauteloso al emitir opiniones sobre los centros de estudio privados de Jaén. Si bien Tomás no estudió en uno de ellos, su hermana Zoila, especialista de la UGEL, cursó durante un tiempo el programa del ISP privado, antes de trasladarse a un ISP público de otra región. Zoila fue la única docente que no realizó cuestionamientos a la educación privada a distancia, y afirmó que no existen diferencias entre la intensidad de la formación que brinda el ISP público y los programas privados.

A diferencia de Zoila, el profesor Patricio denunció categóricamente el carácter mercantilizado de los programas privados a los que acceden los docentes awajún en Jaén:

[...] Antes no había [formación docente privada en la modalidad semipresencial]. Solamente se estudiaba a distancia, pero un estudio que tenías que estar ahí, un pedagógico serio: tres meses tenías que asistir, te sacaban el jugo, te daban chamba [trabajo]. Por eso, Ollanta ${ }^{13}$ dijo que las universidades se han hecho negocio, mercachifle. Lo que el gobierno quiere es que los docentes sean bien preparados, sino no vamos a mejorar. Por ejemplo, ahorita hay decanos que no quieren dejar su cargo; ahí quieren morir porque hay plata. Hay marcha de universitarios; he visto en Chiclayo. Hasta pintas hay amenazando al decano que deje, dándole un plazo para que deje. (2016)

La profesora Ester comentó que los programas de educación a distancia en institutos y universidades privados en Jaén empezaron a surgir hace unos ocho años. Ester, hermana mayor de Zoila y Tomás, criticó que se asista "solo $10 \mathrm{a}$ 15 días", a diferencia del programa de profesionalización docente del que ella

12. Todos los nombres de las personas e instituciones fueron cambiados para mantener sus identidades de manera confidencialidad.

13. Se refiere a Ollanta Humala, presidente de la República en el período 2011-2016. 
egresó en el ISP público de la ciudad de Moyobamba. Su programa brindaba formación para maestros que trabajan hasta hace unos años. Parece coincidir con Patricio en que la formación del ISP público difiere notoriamente de la ofertada por los privados.

El profesor Patricio, como la mayoría de los docentes destacados entrevistados, está de acuerdo con la formación por profesionalización, pero no con los programas privados a distancia de Jaén, en los que la formación profesional no interesa, pues importa más el "negocio". Añade, además, un factor que le permite evaluar la seriedad de una institución: las acreditaciones, que forman parte de la implementación de la Ley de Reforma Universitaria. Al respecto, señala:

Como dijo Ollanta, he visto lo que dice, que muchas universidades con sus programas a distancia no están autorizadas; se están enriqueciendo diciendo que están acreditados, autorizados. Por eso, dijo que ya estos programas a distancia que están capacitando a los docentes se van a cerrar hasta que se acrediten. Caso contrario, están sacando docentes que no valen. En la práctica para enseñanza, cero: no están bien preparados. Entonces, ¿qué enseñanza van a impartir a los niños? También, decía que las universidades están vendiendo títulos, están negociando, se están haciendo platudos. O sea, dicen ya ven firma acá, paga. Diplomados, por ejemplo; hay diplomados que están vendiendo así nomás. (Patricio, 2016)

Elmer, también docente, hace eco de esta crítica al señalar que la modalidad a distancia en los centros privados es como un "engaño", pues son programas autofinanciados por los estudiantes-maestros que no aseguran una titulación y no brindan una oferta educativa que asegure condiciones básicas. Este docente denuncia la naturaleza mercantil e inescrupulosa de los programas de educación superior privados, y exige la presencia de los organismos locales del sector para que controlen la oferta que explota la necesidad de educarse de los estudiantes-maestros awajún. Su posición es planteada en el siguiente comentario:

[...] por eso, yo venía reclamando desde antes que no engañen a nuestros paisanos. En... [la filial de universidad privada de Jaén], no solo estudian de Alto Mayo, de Amazonas; van también bastante jóvenes, pero ¿Cómo hasta ahora bien no pueden recoger su título? Es todo un engaño, un negocio. Es todo irregular. Tienen que empezar desde marzo hasta diciembre. Los jóvenes se van vacaciones. Están pagando dice mensualmente, como si estuvieran estudiando regular, pero al final no tienen título. Eso recién me han comunicado; entonces, ahora bien, no sé ¿Depende de quién?, ¿Quién puede investigar?, ¿Quién puede reclamar? Porque simplemente mis colegas se van desesperadamente a estudiar, a 
trabajar, y de eso se aprovechan, pero eso no podemos dejar. Depende de UGEL. Ellos deben solicitar si estas universidades están autorizadas. Bajo eso, la UGEL de Moyobamba o Rioja deben convocar a los jóvenes que desean prepararse. Es fácil hacer eso, pero hasta ahora no tenemos eso. (Elmer, 2016)

De este modo, el docente denuncia la inacción de las instancias estatales frente a una oferta educativa sin regulación que "engaña" y se "aprovecha" de las expectativas de los awajún por acceder a una educación superior y a un trabajo formal. Como observa al final de la cita, Elmer agrega que los maestros awajún no lograrían obtener el título pedagógico en institutos y universidades privados no acreditados. Este es un aspecto a resaltar, puesto que, es de esperar que, mientras más jóvenes awajún accedan y egresen de la educación privada, tanto más improbable sea que la evalúen de manera crítica. Esto parece sucederle a Zoila, quien es la única docente entrevistada que no tuvo reparos frente a los programas a distancia de las instituciones privadas.

La motivación por financiarse una educación privada parece ser el acceso a un trabajo formal. De hecho, el 70\% de la PEA en Perú trabaja informalmente, porcentaje que es mayor entre pueblos originarios (Cáceres, Cavero y Gutiérrez, 2016). Adicionalmente, existe un déficit de maestros indígenas con formación profesional concluida, lo que genera una alta probabilidad de que sean contratados si son estudiantes indígenas de la carrera de Educación. Chirapaq (2014) desarrolla un estudio en nueve regiones, andinas y amazónicas sobre las dificultades experimentadas por jóvenes indígenas para acceder, permanecer y egresar del sistema educativo superior, y para posteriormente incorporarse al mercado laboral. El estudio halló que, en la muestra de 481 jóvenes, la carrera con una notable mayor demanda era Educación. No obstante, dicha investigación no indagó acerca de las expectativas de los estudiantes indígenas al optar por esta carrera.

\section{- Cuestionamientos de los estudiantes-maestros awajún hacia la educación privada a distancia}

A través de encuestas, se exploró cómo los estudiantes del ISP público de Jaén y la universidad católica de Nueva Cajamarca -instituciones reconocidasconciben la formación ofertada en los programas privados de educación a distancia. Las encuestas indican que la universidad privada en Jaén es "un engaño", "una estafa", "un aprovechamiento de los indígenas", "una explotación", "donde los estudiantes son como esclavos" y "están como en el tiempo del caucho abusados por falta de conocimiento". Además, se cuestiona su baja intensidad, por lo que "los docentes son muy criticados porque solo trabajan con constancia de matrícula", "no los preparan bien; solo pagan", "no es de calidad", "tienen deficiencia en su formación", "no salen formados pedagógicamente", "no son 56 I programas bilingües", "los egresados no saben enseñar", “aprueban a los alum- 
nos que no saben". Critican también su baja rentabilidad, el hecho de que "los egresados manejan moto", "es muy costosa", "es un negocio", "inseguro, porque no tiene programa bilingüe", "no es seguro que salgan licenciados o con título".

Cuenca (2014) precisa que la liberalización del mercado educativo se generó bajo el supuesto de que se produciría mayor democratización en el acceso. Si bien hubo un incremento en el número de jóvenes que van a la universidad, solo el $14 \%$ de jóvenes más pobres acuden a la universidad y existe aproximadamente un $40 \%$ de subempleo profesional (Cuenca, 2014). Además del impacto del crecimiento de la oferta educativa sin regulación en el subempleo profesional, el fenómeno de la privatización de la educación parece participar también en el empleo formal de "no profesionales". La educación superior privada a la que acceden los awajún que laboran en el servicio de EIB en el contexto de un vacío estatal en la formación de maestros indígenas muestra las interrelaciones entre la privatización por defecto y el empleo de estudiantes-docentes con una carenciada preparación para las escuelas EIB del Alto Mayo.

En cuanto al instituto pedagógico privado, este también fue juzgado con reprobación por los estudiantes-maestros del ISP público, aunque en menor medida que la filial de universidad privada. En el mes de enero del 2016, visité el ISP público y pude presenciar una reunión de aproximadamente 60 estudiantes, autoridades del instituto y un excongresista awajún. El excongresista dio a conocer la situación de la filial de universidad privada afirmando que es "un negocio, lucra y no educa". El entonces coordinador del programa bilingüe del ISP público me informó que se improvisó la reunión con la finalidad de que el congresista incidiera en el Ministerio de Educación para la reapertura del programa de titulación para maestros bilingües, pues un buen número de maestros awajún pugnaban por ser admitidos al ISP público. Hacia el final de la reunión, se firmó un acta con todos los presentes, acta que el entonces congresista llevaría al Ministerio de Educación.

En el ISP público, se constató que la educación privada ofertada en Jaén es cuestionada también por los awajún de otras regiones. Estudiantes-docentes awajún de Amazonas gestionaron la llegada del referido congresista desde Lima a Jaén a fin de verificar la situación de la filial de la universidad privada. Además, un grupo de estudiantes-maestros awajún, wampis y achuar realizaron un acta, en la que señalaban unirse al petitorio de la UGEL Nieva, región Amazonas, con la finalidad de que se volviera a abrir el programa de titulación para maestros indígenas en el ISP público de Jaén. De ese modo, la formación docente en el ISP público constituye una demanda central de los estudiantesmaestros de los pueblos awajún, wampis y achuar de regiones como Amazonas y Loreto frente a las deficiencias e irregularidades de las instituciones privadas.

A través de observaciones, se pudo evidenciar los contrastes entre los centros privados de Jaén y el ISP público. El ISP privado opera en limitadas condiciones de infraestructura: tanto la filial de universidad como el ISP no cuentan con una biblioteca. Incluso, en la filial de la universidad, no fue posible acceder a las tesis de los estudiantes, a diferencia del ISP público. El ISP público mostró 
un ambiente limpio, ordenado y amplio. Tiene una biblioteca donde se puede acceder a las tesis de los estudiantes indígenas, una cafetería, espacios para practicar deportes y áreas verdes. Por lo que pude conocer, cuenta con algunos docentes comprometidos con la formación de los maestros indígenas. Por ejemplo, resalta el hecho de que el ISP público ideara maneras de brindar soporte a las maestras-madres fuera del "formato tradicional", como lo es brindar el servicio de cuidado de sus bebés y niños pequeños mientras ellas estudian, lo que les permite concluir su formación.

En síntesis, las instituciones privadas son totalmente rechazadas por los docentes entrevistados (salvo una docente), el líder indígena y los estudiantesmaestros encuestados del ISP público por tratarse de una educación que explota las expectativas de los estudiantes. Sin embargo, la crítica parece arrastrar también a los estudiantes-maestros que acceden a ella, quienes serían considerados responsables de su débil preparación académica.

\section{Reproducción y renovación de desigualdades}

\section{Desigualdad en el sistema educativo}

En este apartado, se ponderan las implicancias de la oferta educativa privada en la reproducción de desigualdad en la EIB y entre los awajún. La reproducción de desigualdad en la EIB se evidencia, por un lado, en la invisibilización que la oferta privada de formación docente supone respecto a la diversidad cultural y lingüística. La formación profesional de los docentes no repara en la diversidad cultural del ámbito donde opera, a pesar de que convoca a maestros indígenas que trabajan en escuelas registradas como EIB. Por otro lado, la desigualdad se refleja y reproduce en la baja intensidad formativa que proporciona a los maestros awajún para trabajar en las escuelas EIB. En la presente discusión, se desarrolla el segundo aspecto, es decir, la débil intensidad formativa educativa que ofrece a los maestros.

Oliart (2007) comprende las profundas contradicciones de la educación peruana en el contexto de un Estado poscolonial y racista, lo que obstaculiza la democratización de la educación. De hecho, Perú se ubica por debajo del promedio en inversión en educación en la región latinoamericana. De acuerdo con Weise y Laguna (2008), el país posee un sistema con mayor grado de exclusión y privatización que sus vecinos Ecuador y Bolivia. Los investigadores enfatizan la diversificación y expansión del sector privado, de manera tal que aproximadamente la mitad de la población universitaria se educa en el heterogéneo sector privado (Weise y Laguna, 2008).

La política de EIB propone una forma de atención de "fortalecimiento cultural y lingüístico" para las escuelas del Alto Mayo, lo que supone la contratación de maestros awajún competentes en lengua awajún y en castellano. Sin embargo, no existió una política de Estado que se ocupe de la formación inicial o de la profesionalización docente de los maestros indígenas. Por el contrario, 
la "Nota 14"14 agudizó esta brecha al colocar la misma valla en la admisión a los ISP privados y públicos para todos los maestros del Perú.

En el contexto de un déficit de maestros indígenas con formación pedagógica, la contratación docente en el servicio de EIB legaliza la contratación de maestros hablantes de lenguas indígenas y sin formación profesional concluida. De este modo, se produce un circuito diferenciado al de la educación no $\mathrm{EIB}$, en que los maestros deben contar con certificaciones pedagógicas en el marco de la política docente conocida como Reforma Magisterial. Los perfiles de los docentes awajún que trabajan en la EIB y los maestros no EIB revelan la configuración de circuitos educativos desiguales.

\section{Desigualdad entre los awajún del Alto Mayo}

Además de las implicancias de la privatización por defecto en la desigualdad en la EIB en el Alto Mayo, se identifican tres expresiones de desigualdad entre los awajún. La primera se refiere a una jerarquización interna entre los docentes. La segunda expresión de desigualdad aborda la escolarización de los niños y niñas awajún a cargo de los estudiantes-maestros con una muy carenciada formación profesional. La tercera evidencia de desigualdad se relaciona con la diferenciación entre las dos márgenes del Alto Mayo, donde se ubican las escuelas y las comunidades awajún que pertenecen a las UGEL Rioja y Moyobamba.

Una primera expresión de desigualdad en el profesorado awajún consiste en una diferenciación interna entre los docentes destacados y algunos estudiantes-maestros en medio de un contexto de condiciones educativas dispares. Esta situación no sería analizada por todos los maestros destacados, lo que, en algunos casos, produce una concepción de élite meritocrática que jerarquiza al profesorado awajún. Esta expresión de desigualdad sería visibilizada a partir de la concepción del trabajo docente como un "hobby" - como lo sugiere el docente Gustavo-, así como a través de la conceptualización de la contratación docente como un "favor", como es señalado por el docente Tobías.

Una muestra de la descalificación que sufren los estudiantes-maestros se observa, principalmente, en las opiniones del profesor Gustavo. El docente considera que los estudiantes-maestros awajún conciben el trabajo docente como un "hobby". De acuerdo con Gustavo, y como efectivamente sucede en el Alto Mayo, un buen número de familias awajún alquilan sus tierras para fines agrícolas. Por ello, agrega Gustavo, los awajún no precisarían de un trabajo asa-

14. El Decreto Supremo 006-2007-ED estableció la calificación de 14 para lograr la admisión en los ISP privados y públicos, lo que debilitó la formación profesional de los maestros indígenas y la institucionalidad de los centros de formación. Se canceló la especialidad de EIB en varios ISP producto del déficit de ingresantes (Córdoba, 2011). Como corolario, algunos postulantes que no lograron pasar la valla se habrían dirigido hacia las facultades de Educación de las universidades privadas (Díaz, 2015). 
lariado, pues podrían vivir de sus rentas. En ese marco, el trabajo docente aportaría un ingreso que no es indispensable para la supervivencia, por lo cual se constituiría como un "hobby". Gustavo comparó las concepciones del trabajo docente por parte de los maestros indígenas y no indígenas en la medida que la subsistencia de los segundos dependería enteramente del trabajo docente. Por ello, para Gustavo, los docentes no indígenas valoran más su labor frente a un docente awajún del Alto Mayo y se interesan más por mejorar su desempeño en el aula.

Sin embargo, el señalamiento de Gustavo contrasta con el hecho de que los estudiantes-maestros awajún se financian una educación superior privada para trabajar y acceder a un salario. Los pueblos indígenas amazónicos representan la forma más extrema de marginación social. Cáceres et al. (2016) muestran que la pobreza es tres veces mayor y la pobreza extrema siete veces mayor en el caso de la población indígena amazónica que en población castellanohablante. Así también, la precariedad del trabajo (medida como informalidad laboral) es mayor en pueblos indígenas amazónicos. Si bien existe heterogeneidad económica entre los awajún del Alto Mayo (Greene, 2009), se trata de una población que habita una de las regiones con la más alta tasa de deforestación en el país, lo que vulnera los medios de vida de esta población. Además, los cambios socioculturales locales y nacionales influirían en el surgimiento de renovados anhelos educativos y profesionales. En paralelo, la configuración histórica del trabajo docente contribuye a hacer atractiva la carrera docente, pues permite cierta estabilidad frente al precario (e informal) mercado laboral (Birgin, 2007). Birgin (2007) explica que el trabajo asalariado es una construcción histórica que permitió la inclusión de los trabajadores en la esfera pública, al mismo tiempo que articula la vida y permite adquirir una identidad social. En esa línea, los estudiantes-maestros buscarían una protección social con el acceso al trabajo docente. De hecho, un docente awajún expresó que un aspecto central del trabajo docente, a diferencia de otros como en las ONG, es el seguro de salud que ampara a su esposa y a su hija menor.

Si el trabajo como docente constituye un "hobby", resulta difícil entender cómo muchos maestros indígenas se interesan y realizan acciones concretas respecto a su profesionalización. Por ejemplo, los maestros awajún se autofinancian una educación privada, un buen número de maestros reclaman la reapertura del programa de titulación del ISP público y algunos maestros gestionan la supervisión de un excongresista awajún sobre una cuestionada universidad privada. Asimismo, si el trabajo docente constituye un hobby, sería difícil explicar las razones por las que los estudiantes-maestros trabajan en escuelas que consideran remotas. De esa manera, el trabajo docente percibido como un hobby da cuenta de la sospecha en torno a los estudiantes-maestros, pues se duda acerca de la relevancia que el trabajo docente supone para los maestros awajún, lo que, además, explicaría las razones por las que no asumen su trabajo con suficiente responsabilidad e interés. 
Otro aspecto que permite visibilizar la diferenciación jerárquica entre el profesorado awajún se relaciona con la contratación docente. Algunos docentes destacados entrevistados conciben la contratación de los estudiantes-maestros en las UGEL como "una oportunidad" y una "facilidad". Según Tobías, especialista de la UGEL:

[...] actualmente los docentes EIB no están preparados, no son profesionales. Estamos dando una pista para que ellos vayan a estudiar a distancia. Entonces, ellos con primer a cuarto ciclo están trabajando. Hay una oportunidad porque todavía los docentes no optan por el título $[\ldots]$.

Al respecto, Teófilo añade: “[...] Por el momento los docentes están estudiando en Jaén a distancia. Ellos trabajan de marzo a diciembre, después en enero y febrero se van a estudiar [..]. Estamos apoyando a ellos porque no hay profesionales [...]" (Teófilo, 2016). La "oportunidad" y la "pista" mencionados por Tobías, así como la "facilidad" señalada por Patricio, hacen referencia al "apoyo" dado a los estudiantes-maestros al contratarlos en las escuelas. Si bien el motivo para contratarlos es precisado (el déficit de maestros indígenas con formación profesional), Tobías parece concebir a la contratación de estudiantes-maestros como un favor que se hace a estos maestros. Se oculta, entonces, el fundamento por el que los maestros awajún trabajan en las escuelas EIB, que es brindar una educación en la lengua materna de los niños y niñas, así como fortalecerla y desarrollarla (Ministerio de Educación, 2016a).

Dicha conceptualización de la contratación de estudiantes-maestros awajún, que la plantea como un favor para su propio beneficio, es problemática por dos razones. Por un lado, se invisibiliza el fundamento real de la contratación de estudiantes, que es el desinterés del Estado por formar a docentes indígenas, razón por la cual no hay un número suficiente de maestros indígenas profesionales. No se puede, en ese sentido, atribuir la responsabilidad únicamente al estudiante-maestro por su baja intensidad formativa. Con todo, la mayoría de los maestros destacados demandan una mejor educación para los estudiantes y señalan las responsabilidades estatales al respecto. Por otro, encubre el fundamento real de la contratación de estudiantes-docentes awajún. Dicha contratación responde a la necesidad de garantizar una educación que parta de los referentes culturales de los pueblos indígenas y que sea en lengua materna (Ministerio de Educación, 2016a). La falta de visibilización de este objetivo repercute en la poca claridad acerca de los objetivos de la política de EIB.

Una segunda expresión de desigualdad entre los awajún se relaciona con las repercusiones de la carente preparación profesional en la escolarización de los niños y niñas, pues los docentes responsables de su educación responden a la endeble preparación pedagógica de los programas privados. La inconsistencia de la formación docente difícilmente desarrolla en los maestros indígenas una reflexión sobre su historia, cultura y lengua subalternizadas. Tampoco, 
profundiza en conocimientos pedagógicos y didácticos necesarios para llevar adelante su trabajo. Antes bien, la pobreza educativa de los estudiantes-maestros refleja que el conocimiento en el Perú está asociado con el lugar que ocupan los individuos en la fragmentada sociedad peruana (Oliart, 2007).

Una tercera expresión de desigualdad entre los awajún se advierte en el hecho de que los estudiantes-maestros del Alto Mayo provienen, mayoritariamente, del ámbito cercano a la Carretera Marginal y a zonas urbanas, las que corresponden a la margen derecha del Alto Mayo, jurisdicción de la UGEL Rioja. En esta zona, existen escuelas de los tres niveles de la educación básica. Por el contrario, en las comunidades ubicadas en la margen izquierda del río Mayo, zona de mayor lejanía a espacios urbanos, y perteneciente a la jurisdicción de la UGEL Moyobamba, la mayoría de escuelas primarias son de tipo unidocente y no existe ninguna escuela del nivel secundario, lo que obstaculiza la culminación de la educación básica. En la margen derecha, son contratados algunos docentes con estudios concluidos del ISP público, mientras que en la margen izquierda todos son estudiantes del ISP privado, así como de la filial de la universidad privada. En otras palabras, la ubicación geográfica condiciona el acceso desigual al sistema educativo entre los niños y niñas awajún del Alto Mayo.

\section{Apuntes finales}

La realidad educativa de los estudiantes-maestros interpela acerca de cómo se vive la relación entre la escuela y los ciudadanos indígenas. En una educación mercantilizada, no existe una comprensión de la educación como un bien social para todos los peruanos, es decir, una educación como un derecho. Además, la sanción del DL 882 en un marco de precariedad regulatoria ha generado un servicio educativo informal que produce renovados mecanismos de desigualdad entre los awajún. De hecho, participa del descrédito que atraviesan los maestros indígenas.

Una mirada propensa a estigmatizar a los docentes podría inscribirse en la lógica de responsabilización de los maestros por el estado de la educación pública, invisibilizando el rol del Estado como principal garante del derecho a la educación. La desvalorización del docente awajún confluiría, también, con el cuestionamiento de la EIB como posibilidad educativa, al ser el docente indígena su principal referente.

Puede existir cierta complicidad por parte de algunos awajún que acceden a los cuestionados centros educativos privados con el objetivo de obtener una certificación que les facilite trabajar como docentes EIB. En esta decisión, la ética sería relegada a un segundo plano y se evidenciaría que la educación privada es experimentada por los awajún del Alto Mayo como un modelo sin valores morales. De acuerdo con Santos y Barclay (2007), algunos jóvenes awajún han alcanzado espacios reconocidos en la sociedad local y nacional. No obstante, no han desarrollado capacidades que les permitan un manejo ético 
del poder acumulado. En este escenario, la educación privada sin regulación estaría acrecentando los problemas morales entre los awajún.

Me gustaría traer a colación la franca opinión de Isaías, activo líder awajún del Alto Mayo, para quien la verdadera explicación detrás del "negocio de la educación" remite a una estrategia tramada por el Estado a fin de mantener a los awajún en condiciones de profunda desventaja. Las palabras de Isaías llevan a pensar en el recelo que poseen muchos indígenas peruanos hacia el Estado. Como sostienen Santos y Barclay, "Las percepciones negativas que los Asháninka, Awajún y Wampis tienen de los blancos nacionales o foráneos, están, sin duda, marcadas por su experiencia histórica con aquellos, plagada de instancias de explotación, epidemias, despojo, matanzas y esclavitud” (2012, p. 38).

En particular, las relaciones entre el Estado y el pueblo awajún remiten a un suceso trágico en la historia reciente. El 5 de junio del 2009 estalló el conflicto conocido como "Baguazo"15, el que, según cifras oficiales, dejó 33 personas (23 policías y 10 civiles) fallecidas, un agente de la Policía Nacional desaparecido, 7 procesos judiciales y ninguna acción contra los responsables políticos, pero sí para los awajún y wampis.

Durante una de mis visitas al ISP público de Jaén, una docente experimentada, quien labora en la institución con una especial dedicación hacia los estudiantes indígenas, me propuso brindar una clase a los estudiantes-docentes. Durante la rueda de presentación, uno de ellos pidió la palabra, se puso de pie e increpó que el expresidente del Perú, Alan García, había insultado al pueblo awajún aduciendo que eran "gente de segunda clase" y "perros". Este hecho me trajo a la mente el imborrable recuerdo de un grupo de unos diez niños y niñas wampis del río Santiago, cuyas edades iban desde los cinco hasta los trece años. Llevaban sus rostros cubiertos con polos y portaban palos de madera en posición vertical, simulando las lanzas que los awajún y wampis llevaban durante el Baguazo. Mientras caminaban por una de las calles de la comunidad, iban gritando en voz en cuello: “ 5 de junio, nos han matado!", en referencia a la fecha en la que ocurrió el enfrentamiento. Estos hechos revelan que el recuerdo del conflicto está presente entre los awajún y wampis, lo que alimentaría un sentimiento que el Estado se ha propuesto exterminarlos (Santos y Barclay, 2012). De este modo, se observa la "desconfianza" de Isaías sobre la existencia de una educación superior tramada por el Estado a fin de perjudicar a su pueblo tenga un innegable fundamento.

Al mismo tiempo, Isaías lleva a pensar en variaciones en las mentalidades de los awajún sobre la educación formal. El acceso a la educación constituyó el anhelo de amplios sectores populares y respondió al deseo de participar en

15. El origen del conflicto se remonta al segundo gobierno de Alan García (2006-2011), período en el que se suscribió un paquete de decretos legislativos que afectaban a las tierras de las comunidades nativas bajo el pretexto que la aprobación de dichas medidas era una condición para implementar el Tratado de Libre Comercio con los Estados Unidos de América. 
condiciones más justas en la sociedad nacional. No obstante, los programas privados de educación de Jaén son definidos como "negocio", "engaño" y "explotación". Incluso, son comparados, por un estudiante del ISP público, con el abuso sufrido por los pueblos indígenas amazónicos durante la época del caucho. Es probable, entonces, que la educación como un "engaño" y una "explotación" produzcan, cuando menos, frustración y una percepción de fracaso entre los awajún que acceden a ella.

La historia peruana ha demostrado que el surgimiento del conflicto armado interno, durante las décadas de 1980 y 1990, estuvo asociado a desigualdades históricas y a la ambigua promesa de la educación, así como a su carácter autoritario. La violencia estalló en el seno del espacio educativo (universidades, institutos superiores pedagógicos y escuelas secundarias) (Sandoval, 2004). Los años de violencia empujan la reflexión hacia la importancia de una educación que no genere falsas promesas de movilidad social y reproduzca desigualdad, lo que estaría ocurriendo entre los estudiantes-maestros awajún debido a la falta de regulación sobre la educación privada y al abandono estatal de la formación profesional para maestros indígenas.

\section{Recomendaciones}

Es innegable que una formación docente inicial implica mayor exigencia y rigurosidad frente a una "profesionalización". Sin embargo, la mayoría de los awajún del Alto Mayo buscan, incansablemente, formarse como docentes mientras trabajan en las escuelas EIB. Procuran, entonces, los programas de bajo costo, a distancia, ubicados en Jaén. La deficiente preparación académica a la que acceden contrasta con el perfil del docente EIB esperado por la Digeibira, así como con el objetivo de "brindar un servicio educativo relevante y pertinente, que garantice la mejora de los aprendizajes de los niños" (Ministerio de Educación, 2016a, p. 21).

A fin de trazar un camino que permita contar con el docente EIB propuesto por el Ministerio de Educación, un primer paso sería (re)conocer sus reales perfiles. Aproximadamente, la mitad de los docentes awajún que trabajan en escuelas EIB en el Alto Mayo son, en realidad, estudiantes de programas que no garantizan estándares mínimos. Precisan ser trasladados a otras instituciones donde puedan acceder a programas de titulación formales a fin de concluir su formación. Se trata de un proceso, por lo que no "resuelve" el presente de muchos niños y niñas awajún cuyos docentes son estudiantes de instituciones irregulares.

Además, frente a la heterogeneidad de la oferta privada y a la falta de información sobre el servicio educativo, es necesario brindar orientaciones a los usuarios indígenas de la educación privada básica y superior. Un reconocido docente awajún señaló que algunos adolescentes indígenas realizan la secundaria en colegios privados a los que asisten los fines de semana y llevan a cabo 64 I dos años escolares en un solo año. Frente a ello, algunas iniciativas - como el 
"Identicole"16 - pueden ser de utilidad para usuarios alfabetizados, que conocen el uso de plataformas informáticas y que tienen condiciones para acceder a estas. En relación con los usuarios indígenas de la Amazonía, se sugiere articular acciones con instituciones y actores regionales y locales - como son los especialistas bilingües de las DRE y UGEL, ONG, congregaciones religiosas-, así como con las organizaciones indígenas regionales y federaciones indígenas locales para que, en coordinación con el Ministerio de Educación y la Sunedu, informen y orienten a las familias y jóvenes indígenas.

16. El Identicole es una herramienta digital que pone a disposición de los padres y madres de familia información sobre las instituciones educativas públicas y privadas. A través de esta, uno puede confirmar, por ejemplo, si dichas instituciones están autorizadas por el Minedu. 


\section{Referencias bibliográficas}

Balarín, M. (2012). El gobierno de la educación en Inglaterra y Perú: una mirada comparada desde la economía política. Lima: Grade.

(2015). Las múltiples formas y efectos de la participación del sector privado en la educación. Lima: Forge.

(2017) La trayectoria reciente y situación actual de la educación privada en el Perú. Lima: Forge.

Ball, S. (2014). Globalización, mercantilización y privatización: Tendencias internacionales en Educación y Política Educativa. Educación y Política Educativa, 22 (41), 1-13.

Ball, S. y Youdell, D. (2007). Privatización encubierta en la educación pública, Londres: Instituto de Educación, Universidad de Londres.

Benavides, M. (2007). Lejos (aún) de la equidad: La persistencia de las desigualdades educativas en el Perú. Investigación, políticas y desarrollo en el Perú. Lima: Grade.

Birgin, A. (2007) Pensar la formación de los docentes de nuestro tiempo. En F. Terigi (Comp.), Diez miradas sobre la escuela primaria. Buenos Aires: Fundación OSDE / Siglo XXI.

Brown, M. (1984) Una paz incierta: Historia y cultura de las comunidades aguarunas frente al impacto de la Carretera Marginal. Lima: Centro Amazónico de Antropología y Aplicación Práctica.

(2014) Upriver the turbulent life and times of an Amazonian people. Cambridge: Harvard University Press.

Cáceres, R., Cavero, O. y Gutiérrez, D. (2016). Diagnóstico descriptivo de la situación de los pueblos originarios y la Política de Educación Intercultural Bilingüe en el Perú. Lima: Ministerio de Educación del Perú.

Consejo Nacional de Educación (2016). Proyecto Educativo Nacional. Balance y recomendaciones 2015 (2da ed.). Lima: Consejo Nacional de Educación.

Córdoba, G. (2011). Educación superior en el Perú: Los pueblos indígenas y afrodescendientes y las políticas públicas e institucionales. En D. Mato (Coord.), Educación superior y pueblos indígenas y afrodescendientes en América Latina. Políticas y prácticas. Caracas: Ielsac / Unesco.

Cuenca, R. (2013). Cambio, continuidad y búsqueda de consenso, 1980-2011. Lima: Fondo Editorial de la Derrama Magisterial.

(2014). La ley es un avance, pero hace falta una reforma real. $L a$ Mula. 29 de junio. Recuperado de https://redaccion.lamula.pe/2014/06/29/ alan-garcia-esta-en-contra-de-todo-lo-que-no-sea-hecho-por-el/ albertoniquen/

Díaz, H. (2015) Formación docente en el Perú. Realidad y tendencias. Lima: Santillana. 
Dubet, F. (2005), La escuela de las oportunidades: ¿Qué es una escuela justa? Barcelona: Gedisa.

(2015). Los postulados normativos de la investigación en educación. Revista Espacios en Blanco, 25, 229-249.

Gentili, P. (1998) El consenso de Washington y la crisis de la educación en América Latina, en ÁLVAREZ-URIA, R.F. (Comp.) Neoliberalismo versus democracia. Barcelona: La Piqueta.

Greene, S. (2009) Caminos y carretera, acostumbrando la indigenidad en la selva peruana. Lima: Instituto de Estudios Peruanos.

Guadalupe, C., Twanama, W. y Castro, M. (2018). La larga noche de la educación peruana: Comienza a amanecer. Lima: CIUP. Recuperado de: http://repositorio.up.edu.pe/bitstream/handle/11354/2184/DD1806. pdf? sequence $=6$

Ministerio de Educación del Perú (2013). Hacia una educación intercultural bilingüe de calidad. Propuesta pedagógica. Lima: Ministerio de Educación. Recuperado de: http://www.minedu.gob.pe/minedu/archivos/a/002/01general/2-propuesta_pedaggogica_eib_2013.pdf

(2016a) Plan Nacional de Educación Intercultural Bilingüe al 2021. Lima: Ministerio de Educación. Recuperado de http://www.grade.org.pe/ forge/descargas/PLAN\%20EIB.pdf.

(2016b) Unidad de Estadística Educativa. Recuperado de: http:// escale.minedu.gob.pe/web/inicio/padron-de-iiee

Montero, C., Ames, P., Uccelli, F. y Cabrera, Z. (2005). Oferta, demanda y calidad en la formación de docentes. Los casos de Cajamarca, Cusco, Piura, San Martín y Tacna. Lima: Dinfocad / Proeduca-GTZ.

Oliart, P. (2007) State reform and resilient powers: Teachers, school culture and the neoliberal education reform in Peru (tesis doctoral). Universidad de Newcastle, Newcastle.

(2011). Mediocridad y corrupción: Los enemigos de la educación pública. En L. Pásara (Ed.), Perú ante los desafíos del siglo XXI. Lima: Fondo Editorial PUCP.

Pease, H. y Romero, G. (2013). La política en el Perú del siglo XX. Lima: Fondo Editorial PUCP.

Rivero, J. (2007). Educación, docencia y clase política en el Perú. Lima: Tarea.

Saavedra, J. y Suárez, P. (2002). El financiamiento de la educación pública en el Perú: El rol de las familias. Lima: Grade.

Sandoval, P. (2004). Educación, ciudadanía y violencia en el Perú: Una lectura del informe de la CVR. Lima: Tarea / Instituto de Estudios Peruanos.

Santos-Granero, F. y Barclay, F. (2007). Guía etnográfica de la Alta Amazonía Volumen VI. Lima: Smithsonian Tropical Research / Instituto Francés de Estudios Andinos. 
(2012). Bultos, selladores y gringos alados: Percepciones indígenas de la violencia capitalista en la Amazonía peruana. Anthropologica, 28(28), 21-52.

Weise, C. y Laguna, J. L. (2008). La educación superior en la región andina: Bolivia, Perú y Ecuador. Avaliação: Revista da Avaliação da Educação Superior 13(2), 425-450. 